\title{
TỪ LÁY VẦN TRONG THƠ TÌNH XUÂN DIỆU
}

\author{
Đặng Thị Lành ${ }^{\mathbf{a}^{*}}$
}

${ }^{a}$ Khoa Ngũ văn và Văn hóa học, Trường Đại học Đà Lạt, Lâm Đồng, Việt Nam

Nhận ngày 03 tháng 11 năm 2015

Chỉnh sửa ngày 29 tháng 02 năm 2016 | Chấp nhận đăng ngày 16 tháng 03 năm 2016

\section{Tóm tắt}

Tù láy thuộc loại đon vị ngôn ngũ đặc biệt của tiếng Việt. Mỗi tù láy chứa đụng trong mình sự thể hiện tinh tế và sinh động về sục cảm thu chủ quan của nguời nói truớc hiện tuợng đời sống xã họi. Đây được xem là phuơng tiện tạo hình đắc lưc của văn học nghệ thuật, đặc biệt là thi ca. Mỗi nhà tho, nhà văn đều có nhũng cách sủ dụng tù láy mang tính sáng tạo riêng. Chính điều này đã tạo nên phong cách cá nhân, khả năng tạo tù đặc sắc của người nghệ sĩ. Bài viết duới đây sẽ khảo sát về tù̀ láy vần trong tho tình Xuân Diệu, qua đó khẳng định tài năng sáng tạo tù ngũ rất riêng của nhà tho.

Từ khóa: Từ láy; Từ láy vần; Thơ tình; Xuân Diệu.

\section{1. ĐặT VẤN ĐỀ}

Từ láy là kết quả của một trong năm phương thức cấu tạo từ, nó mang trong mình những đặc trưng có tính chất loại hình tiếng Việt cũng như các ngôn ngữ đơn lập khác ở phương Đông. Không giống với những loại từ ngữ khác, từ láy hiện diện không chỉ nhằm phục vụ mục đích giao tiếp đơn thuần. Nét nổi bật của loại đơn vị này là nét gợi hình, gợi cảm của chúng. Bởi vậy, đây chính là loại chất liệu điển hình của văn học nghệ thuật, mà đặc biệt là thơ ca.

Truyền thống văn học nước nhà đã chứng minh điều đó. Các thi sĩ lớn của dân tộc đều là những bậc thầy trong việc sử dụng và khai thác loại chất liệu này để phục vụ cho sự nghiệp văn học của mình. Tiêu biểu là các tác gia, như Đoàn Thị Điểm, Nguyễn Du, Hồ Xuân Hương và sau này là các nhà thơ mới, như Hàn Mạc Tử, Nguyễn Bính... Xuân Diệu - nhà thơ mới nhất trong các nhà thơ Mới cũng đã sử dụng rất linh hoạt, rất

\footnotetext{
*Tác giả liên hệ: Email: lanhdt@dlu.edu.vn
} 
riêng các từ láy để làm nên "cái nguồn sống rào rạt chưa tùng thấy ở chốn nước non lặng lẽ này (...) Khi vui cũng nhu khi buồn, người đều nồng nàn tha thiết” [2; tr.138].

\section{MộT VÀI NHận XÉT CHUNG VỀ VIỆC SỬ DỤNG TÙ̉ LÁY TRONG TậP THƠ TÌNH XUÂN DIỆU}

Khảo sát toàn bộ tập Tho tình Xuân Diệu (GS. Hà Minh Đức tuyển chọn \& giới thiệu, 2009, Nxb Văn học) gồm 87 bài thơ, chúng tôi đã nhận diện, thống kê được 264 từ láy được tác giả sử dụng tới 412 lần trong tổng số 387 câu thơ có từ láy. Như vậy, bình quân mỗi bài thơ có 3 từ láy nhưng trong số 87 bài thơ chúng tôi đã khảo sát, có 2 bài thơ tác giả không sử dụng 1 từ láy nào (Nguyên Đán và Nguyện) cho nên bình quân số từ láy thực tế trong mỗi bài thơ sẽ cao hơn 3 từ láy, với tần số xuất hiện là 5 lần trong 1 bài thơ.

Với 264 từ láy được nhà thơ sử dụng 412 lần, có nghĩa một số từ láy đã được nhà thơ lặp đi lặp lại nhiều lần. Thực tế, có khá nhiều từ láy được Xuân Diệu sử dụng tới hàng chục lần nhưng lại diễn tả những ý nghĩa khác nhau trong từng ngữ cảnh cụ thể, tùy thuộc vào vị trí của từ láy trong câu. Điều này cho thấy ông là người rất ưa dùng từ láy và có cách dùng rất riêng, mang đầy tính sáng tạo. Qua những từ láy ấy, ông đã $k y$ cóp nhiều sự việc và lời ăn tiếng nói khá độc đáo, sinh động từ cuộc sống để đưa vào thơ ca: "Một số bài tho đã vọt ra trục tiếp tù cái vốn tươ rói, nóng hổi ấy mang theo cả cái bộn bề ú tràn của cuộc sống” [10; tr.62].

Trong cả tập thơ, không thấy xuất hiện hiện tượng từ láy được tách ra và xen vào một tiếng (từ) giữa hai thành tố của một từ láy đôi bởi con người ham yêu khát sống, luôn cuống quýt như Xuân Diệu thì cần phải giục giã, vội vàng trước sự chảy trôi không ngừng của thời gian. Ông không muốn có sự xa cách hay trắc trở nào trong cuộc sống. Chính quan niệm này được nhà thơ mang vào trong từng trang viết, trên từng câu chữ qua việc sử dụng, tổ chức từ với từ thành những đơn vị của phát ngôn lớn hơn đó là ngữ, câu và đặt từ láy vào những vị trí thích hợp để làm tăng thêm giá trị nghệ thuật và giá trị biểu cảm cho lời thơ. 
Từ láy sử dụng trong tập thơ chủ yếu là loại tính từ và động từ. Sự có mặt của từ láy là phụ từ và danh từ là không đáng kể. Theo số liệu chúng tôi đã thống kê được, chỉ có 5 từ láy thuộc loại danh từ (nơi nơi, chiền chiện, buơm bưóm, là lụa, ai ai) và 5 từ láy thuộc loại phụ từ (sắp sủa, thỉnh thoảng, mãi mãi, luôn luôn, lắm lắm). Do vậy, từ láy là động từ và tính từ là đối tượng quan tâm chủ yếu của chúng tôi.

Trong quá trình khảo sát toàn bộ tập thơ, chúng tôi cũng nhận thấy Xuân Diệu sử dụng rất nhiều lần một số từ như: tâm twởng, tịch mịch, triền miên, tơ twởng...nếu xét về ngữ nghĩa đây chưa hẳn đã là những từ láy nhưng nếu xét về hình thức thì đây là những từ có phương thức láy nên chúng tôi đã đưa vào nghiên cứu để tiện cho việc khảo sát, phân loại.

Các số liệu cụ thể về từ láy xuất hiện trong tập thơ được thể hiện trong các bảng thống kê sau:

Bảng 1. Số lần xuất hiện của từ láy trong tác phẩm

\begin{tabular}{lll}
\hline Các kiểu láy & Số lần xuất hiện & Tỉ lệ \\
\hline Hoàn toàn & 91 & $22.1 \%$ \\
Điệp vần & 66 & $16.0 \%$ \\
Điệp âm & 255 & $61.9 \%$ \\
\hline Tổng số & 412 & $100 \%$ \\
\hline
\end{tabular}

Bảng 2. Số lượng từ láy theo cấu tạo

\begin{tabular}{llll}
\hline Các kiểu láy & Số từ & Tỉ lệ & Số câu thơ có từ láy âm \\
\hline Hoàn toàn & 60 & $22.7 \%$ & 86 \\
Điệp vần & 43 & $16.3 \%$ & 63 \\
Điệp âm & 161 & $61.0 \%$ & 238 \\
\hline Tổng số & 264 & $100 \%$ & 387 \\
\hline
\end{tabular}

\section{TÙ ĐIỆP VÀ̀N}

So với từ láy hoàn toàn và từ điệp âm thì từ điệp vần có số lượng thấp hơn cả. Tuy vậy, tiểu loại từ này vẫn có một vai trò nhất định trong việc biểu hiện cảm xúc, cảm giác mãnh liệt, dữ dằn với người, với đời của nhà thơ. 
Khảo sát toàn bộ tập thơ chúng tôi nhận diện được 43 từ điệp vần xuất hiện 66 lần. Có một số từ tác giả sử dụng khá nhiều lần như: bồi hồi, lác đác, êm đềm...

Trong 43 từ điệp vần thì hầu hết là các từ đứng trước có thanh điệu giống với thành tố đứng sau. Có một số ít từ có thanh điệu khác như: âm thầm, lần khân, phẳng lặng, điu hiu. Vai trò tiếng gốc trong các từ trên có xu thế mờ dần, vì vậy khi xem xét ý nghĩa của từ, ta phải dựa vào cả chỉnh thể chứ khó mà có thể đối chiếu với tiếng gốc để tìm ra ý nghĩa chung của từ.

\subsection{Từ điệp vần là động từ}

Tiểu loại này trong toàn tập thơ xuất hiện là các từ: bịn rịn, lảng đảng, lần khân, la đà, lòa xòa, lim dim, phân vân...

Động từ là lớp chuyên dùng để diễn tả hoạt động, trạng thái của người, sự vật, sự việc nhưng điệp vần động từ ngoài những chức năng ấy ra nó còn có khả năng biểu thị trạng thái, hoạt động với giá trị hình tượng, gợi cảm cụ thể hơn mà các động từ khác không thể thay thế được.

Ví dụ:

Mải nhìn bịn rịn lo em ốm

Cảnh lả tả chờ tay ai đón đẩy
(Mặt em)

(Hoa đêm)

Thiên nhiên trong thơ Xuân Diệu hiện lên đều có hình, có khối, có sự hoạt động không ngừng nghỉ giống như sự lao động miệt mài của chính ông. Cỏ, lá, hoa, trăng, vườn... tất cả đều có những tiếng nói riêng, cử chỉ riêng dù là ngày hay đêm. Ngay cả cái khoảnh khắc bóng đêm buông xuống cũng được ông viết:

Ngang vai đêm tới la đà

(Mượn nhà vũ trụ)

Trong câu ca dao xưa có "cành trúc la đà” thì với Xuân Diệu lại là "bóng đêm la đă”. Cái ý niệm về bóng đêm đang tới chậm chạp, nhẹ nhàng thì cũng có nghĩa là thời 
gian đang trôi qua, vì vậy phải biết nắm bắt từng phút, từng giây của sự sống. Đây chính là một cách níu giữ thời gian trong thơ ông.

Trong số các từ điệp vần là động từ thì Xuân Diệu chỉ sử dụng duy nhất một từ phân vân tới 2 lần.

Lần thứ nhất:

Con cò trên ruộng cánh phân vân

(Thơ duyên)

Theo Từ điển tiếng Việt, phân vân có nghĩa là đang mải nghĩ, chưa biết quyết định như thế nào. Ở đây có sự đối lập giữa cái phân vân với cái gấp gấp ở câu trên (Mây biếc về đâu bay gấp gấp) bởi một bên thì gấp gáp, vội vã còn một bên thì lại đang phân vân, chưa đưa ra được quyết định. Vì vậy, con cò trên ruộng cứ lững lờ đôi cánh, không biết nên bay cao hay bay thấp, bay gần hay bay xa, nhập vào đồng ruộng hay lên khoảng trời xanh. Và một câu hỏi đặt ra: về đâu? Không có câu trả lời nào nên trở thành thứ dư âm vô vọng. Tâm trạng phân vân của cánh cò cũng như cái gấp gấp của làn mây biếc là một tâm trạng rất riêng biệt, điển hình của thơ Mới mà chưa có trong thơ cổ bởi “Cái phân vân của cánh cò, cái gấp gáp, vội vã của làn mây là biểu hiện của một cái "tôi " ý thức rõ rệt về thòi gian và sụ hạn hũu của con người, của đời người" [6; tr.285].

Lần thứ hai:

Reo ái tình trong nhịp máu phân vân

(Đêm thứ nhất)

Phải nói Xuân Diệu là bậc thầy trong nghệ thuật cấu tứ và đặt từ đúng chỗ bởi chỉ đến Xuân Diệu mới có cái phân vân của nhịp máu chảy. Những tưởng sự tuần hoàn của máu là vô hình, vậy mà nhà thơ đã thức nhọn giác quan để biến nó thành hữu hình. Nhịp máu tuổi trẻ của những chàng trai, cô gái đang độ xuân thì cũng phải đắn đo khi quyết định cho những hẹn hò, những người tình trong buổi tối cuối tuần thi vị. Hoài Thanh cho rằng: "Xuân Diệu đã gưi trong tho của người lẫn với một chút hương xưa của đất nước, bao nhiêu nồi niềm riêng của thanh niên bây giờ" [8; tr.117]. 


\subsection{Từ điệp vần là tính từ}

Từ láy điệp vần là tính từ được tác giả sử dụng như: phẳng lặng, lũng thũng, lũng đũng, lao đao, lâm râm, chói lói, choi vơi, bồi hồi, bõ ngõ̃, khéo léo...

So với điệp vần động từ thì điệp vần tính từ có số lượng cũng như số lần xuất hiện lớn hơn hẳn.

Trước hết là do trong vốn từ láy âm của tiếng Việt, những từ láy âm là tính từ vẫn có số lượng nhiều hơn cả. Thứ hai, Xuân Diệu là một trong những "chủ tướng của dòng thơ lãng mạn quá khứ” (Đoàn Hương) với lòng ham yêu, khát sống, quấn quýt giao cảm với đời, dù là chút tình vụn, mảnh tình con thì những từ điệp vần là tính từ rất phù hợp để mô tả những bữa tiệc trần gian của tác giả. Nó giúp cho cuộc sống trở nên thiêng liêng hơn, đầy đủ hơn, ý nghĩa hơn. Trong số những từ điệp vần là tính từ, Xuân Diệu chỉ sử dụng hai từ mô phỏng âm thanh là lách tách, lâm râm:

Lâm râm mưa chuyển trên cành

(Mưa)

Nguyệt lác đác tiếng nở giòn lách tách

(Hoa đêm)

Về từ láy mô phỏng âm thanh, theo Hoàng Văn Hành, có hai loại từ láy biểu trưng hóa ngữ âm đơn giản. Loại thứ nhất là những từ láy mô phỏng trực tiếp gần đúng âm thanh nhất. Loại thứ hai gồm những từ láy mà sự mô phỏng âm thanh chỉ là hình thức bên trong còn chức năng chính của nó đã gọi thành tên sự vật hay hiện tượng, quá trình phát ra âm thanh do từ mô phỏng. Đó vốn cũng là những từ tiếng vang, từ tượng thanh nhưng đã được chuyển nghĩa theo phép hoán dụ, được dùng để biểu trưng cho sự vật, hệ quả hay quá trình phát ra âm thanh. Do vậy, nghĩa của từ láy điệp vần với những nét nêu trên "bao giờ cũng là sụ mô phỏng âm thanh lặp đi lặp lại với cuờng độ hoạc âm sắc khác nhau" [7; tr.88] đủ cho thấy rằng các từ đang xét không còn dừng lại ở sự mô phỏng âm thanh thuần túy nữa, vì giá trị sử dụng hòa phối ngữ âm ở đây đã lớn hơn nhiều. 
Những từ láy vần tính từ chỉ dáng điệu, được Xuân Diệu sử dụng như: lũng đũng, lũng thũng, luớt thướt...

Ví dụ:

Gió lướt thướt kéo mình qua cỏ rối

Lòng buồn lũng thũng vương sau áo
(Tương tư chiều)

(Tình qua)

Đặc biệt là câu:

Anh đi lũng đũng chẳng theo gần

(Thơ duyên)

Dường như Xuân Diệu đã đi đến tận cùng xứ sở để thấy hết được những trạng thái, cảm xúc của tình yêu và tuổi trẻ, hạnh phúc và khát khao, cô đơn và xa cách. Cái lĩng đũng của chàng trai đối lập với cái điềm nhiên của cô gái ở câu thơ trước đó (Em bước điềm nhiên không vuớng chân). Dùng lũng đũng chứ không phải lũng thũng, bởi đi như thế vừa tình tứ, vừa giữ được khoảng cách với người yêu. Nếu thay từ lũng thũng vào đó thì chỉ còn là dáng điệu thong thả, chậm rãi đơn thuần, không có có gì vội vàng, mất đi cả cái “thơ" trong buổi chiều hẹn hò đầy “duyên” ấy. Đây mới đúng là phong cách thơ Xuân Diệu.

Nhà thơ cũng đã sử dụng khá nhiều từ láy chỉ tính chất, mức độ để miêu tả cảnh sắc, con người:

Ví dụ:

Sương the lảng đảng bạc cây tùng

Khắc giờ tan lụi, dạ chon von

Hình non bảng lảng sương thôn dịu hòa
(Ngẩn ngơ)

(Hết ngày hết tháng)

(Mượn nhà vũ trụ)

Bên cạnh đó Xuân Diệu cũng dùng một số từ điệp vần tính từ chỉ trạng thái, cảm xúc như: tưng bìng, bồi hồi, chơi vơi, lao đao...

Ví dụ: 
Tương tư nâng lòng lên chơi vơi

Thoảng tay tình gió vuốt - bỗng lao đao
(Nhị hồ)

(Hoa đêm)

Đặc biệt, Xuân Diệu đã mượn cảm xúc bồi hồi của cái bóng để nói lên cái cảm xúc, tâm trạng của nhân vật trữ tình trong bài thơ. Đó là nỗi niềm của cả hai người cùng nghĩ về một hướng:

\section{Bóng người cùng với bóng ta bồi hồi}

(Mượn nhà vũ trụ)

Tình yêu trong thơ Xuân Diệu luôn có gì đó rất lạ, đó là một khát khao, một nỗi ám ảnh về tình yêu, là tiếc nuối, là giấc mơ của những giấc mơ về tình yêu.

Láy điệp vần tính từ cũng có khả năng tăng cường hoặc giảm nhẹ mức độ của sự vật được miêu tả như: lo tho, chói lói, chót vót...

Ví dụ:

Mưa $l o ̛$ pho như dạ khóc âm thầm

Núi cao chót vót chon von

Đốt muôn nến sánh mặt trời chói lói
(Yêu mến)

(Giục giã)

Nhìn chung, từ điệp vần là động từ và tính từ trong thơ tình Xuân Diệu thường có khả năng đánh giá, biểu thị trạng thái, hoạt động với giá trị tượng hình cụ thể và chúng được khéo léo đặt vào những vị trí khác nhau trong từng câu thơ, từng bài thơ. Có thể nói tác giả đã dùng rất nhiều lần và rất đạt các động từ chỉ hành động và trạng thái tâm linh của cái “tôi” trữ tình, của các nhân vật trữ tình để biểu hiện lòng ham yêu khát sống của chính nhà thơ.

\section{KẾT LUẬN}

Có thể thấy trong toàn bộ tập thơ tình, Xuân Diệu đã sử dụng một số lượng từ láy không nhỏ và rất đa dạng về kiểu láy để miêu tả cảnh sắc thiên nhiên, tình yêu con người, tình yêu cuộc sống. Tuy nhiên, những từ láy được ông ưa dùng là những từ láy 
đôi thuộc kiểu loại động từ và tính từ để biểu thị cái rạo rục của thuở ban đầu đầy luuu luyến, cái thất vọng, đắng cay của tình cho đi mà không được nhận lại bao giờ, như chính lời nhà thơ đã bày tỏ: "Đây là hồn tôi đương thời sôi nổi, đây là hồn tôi vừa lúc vang ngân và đây là tuổi xuân của tôi, và đây là sự sống của tôi nữa (...) tôi gửi hồn tôi cho nhũng ngưòi trẻ tuổi và nhất là nhũng nguoòi trẻ lòng” [9; tr.130].

\section{TÀI LIỆU THAM KHẢO}

[1] Nguyễn Tài Cẩn (1996), Ngũ pháp tiếng Việt, Nxb Đại học Quốc gia Hà Nội.

[2] Hoài Thanh - Hoài Chân (2004), Thi nhân Việt Nam 1932 -1945 (bản in lần thú 12), Nxb Văn học, Hà Nội

[3] Văn Tân, Nguyễn Văn Đạm (chỉnh lý và bổ sung) (1994), Tù điển tiếng Việt, Nxb Khoa học Xã hội, Hà Nội.

[4] Hà Minh Đức (tuyển chọn và giới thiệu) (2007), Xuân Diệu - Ông hoàng của tho tình yêu, Nxb Giáo dục, Hà Nội.

[5] Hà Minh Đức (giới thiệu - tuyển chọn) (2009), Tho tình Xuân Diệu, Nxb Văn học, Hà Nội.

[6] Bích Hà (2006), Xuân Diệu một cái tôi khao khát nồng nàn, Nxb Hội Nhà văn, Hà Nội.

[7] Hoàng Văn Hành (1985), Tù láy trong tiếng Việt, Nxb Khoa học Xã hội, Hà Nội.

[8] Tôn Thảo Miên (2002), Thơ thơ và Gửi hương cho gió - Tác phẩm và du luận, Nxb Văn học, Hà Nội.

[9] Nguyễn Đình Chú - Trần Hữu Tá (2002), Văn học 11 (tập một- Phần Văn học Việt Nam), Nxb Giáo dục, Hà Nội.

[10] Lưu Khánh Thơ (1999), Xuân Diệu về tác gia và tác phẩm, Nxb Giáo dục, Hà Nội. 


\title{
RHYMING WORDS IN XUAN DIEU'S POEMS OF LOVE
}

\author{
Dang Thi Lanh ${ }^{\mathrm{a}^{*}}$
}

${ }^{a}$ The Faculty of Literature and Cultural Studies, Dalat University, Lamdong, Vietnam

"Corresponding author: lanhdt@dlu.edu.vn

Article history

Received: November $03^{\text {rd }}, 2015$

Received in revised form: February $29^{\text {th }}, 2016$

Accepted: March 16 ${ }^{\text {th }}, 2016$

\begin{abstract}
Reduplication is a special part of Vietnamese language. Each reduplicative word itself shows its user's exquisite and vivid appreciation of social phenomena. Therefore, reduplication is considered an effective means of expression in literature and art, especially in poetry. Each writer or poet has his/her own ways of using reduplication, which forms the writer's uniqueness and creativity in word forming. This article will focus on rhyming words in Xuan Dieu's poems of love, through which the article reaffirms his distinct creativeness in word usage.
\end{abstract}

Keywords: Poems of love; Reduplicative word; Rhyming word; Xuan Dieu. 